\title{
La escritura de la historia: una aproximación a la Teoría del Relato de Jean Pierre Faye
}

\section{The writing of the history: Jean Pierre Fave an approach to the theory of story}



\author{
Alfredo Gómez Palomino ${ }^{1}$ \\ Universidad de San Buenaventura, Colombia
}

1 Licenciado en historia Universidad del Valle. Magister en Estudios Politicos Pontificia Universidad Javeriana y Candidato a doctor en Educación, Universidad de San Buenaventura-Cali. El artículo es adaptación del acápite Metodología de la Tesis doctoral: Lenguaje Escolar en Colombia: 1825-1950. Aceptabilidad y lenguajes durante los regímenes de instrucción y educación. Correo electrónico:algopa629@hotmail.com 


\section{Resumen:}

La tradición de la escritura de la historia en Colombia durante el siglo diecinueve y buena parte del siglo veinte fue elemento decisorio en la formación del Estadonación. Esta tradición después de los años ochenta del siglo pasado, marca el comienzo de otras posibilidades para el oficio historiador; entre las posibilidades se permite la profesionalización del historiador. La producción de la escritura profesional y universitaria de la historia ofrece a la comunidad académica un acervo de antecedentes para la reflexión sobre la escritura de la historia. Una reflexión en este sentido es posible con la aproximación a la Teoría del Relato del filósofo e historiador francés Jean Pierre Faye. El artículo presenta la postulación de los principios metodológicos de la Teoría del Relato, particularmente, explica las influencias teórico-metodológicas de la racionalidad kantiana, de la economía política marxista, de la sociología sagrada o del poder, y de la lingüistica chomskiana. La aproximación a la Teoría del Relato, presenta una tradición de escritura de la historia, novedosa para el medio académico nacional que se muestra potente para los estudios de historia social y política.

Palabras Claves: Historia, Escritura, Lenguaje hablado, Lingüistica.

\section{Abstract:}

The tradition in writing of the history in Colombia during the XIX century and XX was a key element in the formation of State-Nation. This tradition, after the 1980 s of the past century, marks the beginning of other possibilities for the historian. Among those possibilities, the professionalization of the historian. The production of professional and academic writing of the history offers to the academic community a collection of precedents for the reflection of the writing of the history. A reflection in this way is possible with the approach to the Theory of Story of Jean Pierre Fave, philosopher and historian. This work introduces the postulation of methodological principles of the Theory of History and, particularly, it explains the influences of the theoreticmethodological rationality of Kant, of the economical Marxists politics, of the sacred sociology or power, and of the Chomskian linguistics. The approach of the Theory of History shows a tradition of the writing of the History, which is novel for the national academic environment and that is powerful to study social and political History. 
Keywords: History, Writing, Spoken language, Linguistics.

\section{L'écriture de l'histoire : une approche à la Théorie du récit de Jean Pierre Fave}

\section{Résumé:}

La tradition de l'écriture de l'histoire en Colombie pendant le siècle XIX et de manière significative le XX fut l'élément décisif dans la formation de l'État-Nation. À partir du commencement des années 80 s du siècle antérieur, cette tradition-là commence à évidencier le début d'autres possibilités pour le métier de l'historien. La production de l'écriture professionnelle et universitaire de l'histoire offre à la communauté académique un héritage d'antécédents pour la réflexion sur l'écriture de l'histoire. Une réflexion dans ce cas est possible avec l'approche à la Théorie du Récit du philosophe et historien français Jean Pierre Fave. L'article présent le ramassage des principes méthodologiques de la Théorie du Récit, concrètement, cela explique les influences théorique-méthodologiques de la rationalité Kantienne, de l'économie politique Marxiste, de la sociologie sacrée ou pouvoir, et de la linguistique Chomskienne. L'approche à la théorie du Récit présente une tradition d'écriture de l'histoire, innovante pour le domaine académique nationale qui se montre puissante pour les études de l'histoire sociale et politique.

Mots-clés: histoire, écriture, langue parlée, linguistique. 


\section{A escrita da história: uma aproximação da Teoria do Relato de Jean Pierre Faye}

\section{Resumo:}

A tradição escrita da história na Colômbia durante o século XIX e parte do século XX foi um elemento decisório na formação Estado-nação. Esta tradição depois dos anos oitenta no século passado, marcam o começo de outras possibilidades para o ofício de historiador; entre as possibilidades se permite a profissionalização do historiador. A produção da escrita profissional e universitária da história fornece à comunidade académica um acervo de antecedentes para a reflexão sobre a escrita da história. Uma reflexão neste sentido é possivel com a aproximação da Teoria do Relato do filosofo e historiador francês Jean Pierre Faye. $O$ artigo apresenta a postulação dos princípios metodológicos da Teoria do Relato, particularmente, explica as influências teórico-metodológicas da racionalidade kantiana, da economia política marxista, da sociologia sagrada ou do poder, e da linguística chomskiana. A aproximação da Teoria do Relato, apresenta uma tradição na escrita da história, novidade para o medio académico nacional que se mostra potente para os estudos de história social e política.

Palavras-chave: história, escrita, linguagem falado, linguística. 
La concepción de la historia como relato, particularmente, implica una detenida reflexión sobre la escritura de la historia. En este sentido en el país, por ejemplo, los textos de los historiadores Jorge Orlando Melo y Alexander Betancourt Mendieta ${ }^{1}$, señalan cómo desde los años ochenta del siglo pasado entre el quehacer de los historiadores colombianos surge una preocupación sobre el oficio que, establece como indispensable una revisión de las tradiciones de escritura de la historia.

En el siglo anterior desde los años sesenta en Europa, el debate sobre las tradiciones de escritura de la historia, compele a la tradición historiográfica francesa a entregar importantes alternativas para la revaluación del oficio historiador. Durante este debate continental, es el filósofo e historiador francés, Jean Pierre Faye, que se muestra como un activo contradictor, su propuesta se sostiene con los elementos metodológicos de la Teoria Estándar Extendida Revisada; Teoría analítica del también debate estructuralista de los años sesenta sobre la lingüística generativa. Por virtud de las derivaciones aplicativas de este debate lingüístico, J.P. Faye presenta a mediados de los sesenta su tesis doctoral ${ }^{2}$ que, de hecho se convierte en una alternativa para la escritura de los estudios históricos sobre el fascismo alemán e italiano del período de entreguerras. La alternativa para la escritura de la historia es la Teoría del Relato3; teoría que entrecruza elementos de una topología de los sistemas (de las ideas, económico y político); una sociología del poder y, una crítica de la razón y economía narrativa.

La Teoria del Relato, de manera fundamental, contiene una apuesta metodológica, para develar el sentido y la producción de aceptabilidad de las secuencias de narraciones, o versiones de los lenguajes de la historia. La Teoria del Relato adopta el principio de no centrar exclusivo estudio de la «estructura superficial», sino también estudiar la «estructura profunda», el estudio conjunto de ambas estructuras permite explicar las singularidades de sentido en las cadenas de narración. Esta asunción metodológica fayeana, se traduce, como el principio rector

1 Se trata del artículo de J.O. Melo: Medio siglo de historia colombiana. notas para un relato inicial, Estudios Sociales, 4, 1999. Y la obra de A. Betancourt: Historia y Nación: tentativas de la escritura de la historia de Colombia, 2007, La carreta Editores.

2 Tesis comercialmente (1972) titulada Langages totalitaires. Critique de la rasoin et de l'économie narrative que en 1974 por la editorial Taurus se pública en español con el título: Los Lenguajes Totalitarios.

3 La teoría es producto del pensamiento teórico del filósofo francés que se rastrea en publicaciones cómo: El relato único (1967); Teoría del relato (1972) y La Crítica del lenguaje y su economía (1973). 
de la Teoría del Relato que, parte de la nodal consideración del estudio crítico de la estructura sintáctica de las secuencias o versiones de narraciones en los relatos de la historia. La crítica de la razón y economía narrativa de particulares enunciados en las secuencias de narración de un relato, por ejemplo, permite explicar las distintas posiciones; las posiciones se entienden en la Teoría del Relato de Faye, como los enunciados claves de las distintas figuras (estadistas, intelectuales, académicos y líderes políticos y gremiales), enunciados con implicancias de acción y efectos, por ejemplo, los enunciados en el juego de transmisión o desplazamiento producen distintos efectos (a veces impredecibles), como el caso de las posiciones con los efectos de ideología en el tejido de la trama narrativa.

El estudio crítico de la narración histórica en el entendido de un proceso de escritura (texto), como relato, precisamente $y$, en forma adjetiva, es la capital tarea epistemológica de Faye. Con la Teoría del Relato, el historiador francés hace conjunto tratamiento crítico de las «estructuras superficial y profunda» ${ }^{1}$ de los lenguajes, esto se impone por la necesidad de explicar la razón y economía narrativa y, la aceptabilidad de sentido de las distintas versiones o secuencias de narración. El estudio de estos elementos que circulan en toda la superficie del campo de narraciones, permite develar: trazos, cortes (rupturas o discontinuidades), desplazamientos, incrustaciones, enmarañamientos (vecindades) que se enuncian en los lenguajes de la historia. Entonces, la particular crítica de la «estructura profunda» propuesta por Faye permite, en la escritura de la historia, la descripción y explicación de un amplio campo de posiciones u oscilaciones ideológicas; a la vez, la atención de la «estructura superficial», permite para la escritura de la historia, la observación en el archivo ${ }^{2}$ de las emisiones y, circulación en los relatos o discursos, de unidades de lenguaje (vocablos o palabras-ideas, sintagmas o fórmulas e incrustaciones) contemporáneas unas de otras que hacen aceptable, por ejemplo, la posición (con sus efectos) de una figura o institución en un relato.

1 Faye estudia estas estructuras de los textos hablados y escritos porque considera que, las estructuras en su transformación producen efectos que no se hacen captables con el estudio de una sola estructura. La «estructura profunda» comprende el campo de una serie de posiciones (osciladores ideológicos). Y la «estructura superficial» comprende la partición de los relatos (discursos) contemporáneos unos de otros que, enuncian y hacen aceptable determinada acción.

2 La noción conceptual de bibliografia no es relevante en la perspectiva metodológica fayeana, este historiador hace atención del cuadro de referencias, esto es, del registro de textos que se refieren entre sí. 
En la Teoría del Relato, la crítica de la razón y economía narrativa, se entiende en el horizonte kantiano junto con el enfoque de la lógica articulatoria que Carlos Marx usa en la obra El Capital (Das Kapital), uso que privilegia estudio sobre la dialéctica relación entre política y economía. El análisis marxiano destaca la producción como el interés supremo de la sociedad capitalista y, esto porque, la producción masiva es el factor constante de la 'revolución industrial' desde mediados del siglo diecinueve, y a la vez, es precedente de la revolución científica del siglo veinte que, entroniza la acuñación del elemento capitalista de productividad en la más pura dimensión ideológica, esto es, como un objetivo económico masivo y planetario.

En este sentido, la concepción fayeana de la historia, toma el proceso de la revolución industrial para unificar los campos económico, político, ideológico y de las narraciones en un campo único; la unificación de estos campos, es la concreción del 'campo de la historia,' campo este como una superficie de unidad que junto con la consideración del campo como superficie de narraciones o relato y no como saber, permite el estudio crítico de las secuencias de narración o versiones en los lenguajes. En ese campo unificado, o campo de la historia se surte la crítica que somete los fragmentos o secuencias de narración a un desenmascaramiento de sus articulaciones sintácticas, al desprenderlos, de su contexto y presentarlos en la forma de fragmentos referenciales o de testimonio de acciones con sus efectos, esto es, los fragmentos referenciales como importantes trazos de los lenguajes de la historia.

Faye, en el corpus de la Teoria del Relato, atiende en importancia el análisis automático ${ }^{3}$ del discurso del filósofo francés Michel Pêcheux (1969). M. Pêcheux filósofo marxista, enfoca sus estudios en análisis de la ideología y el discurso; la obra de Pêcheux, es cruce de filosofía, psicología y lingüistica. El análisis automático del discurso de Pêcheux es una modalidad de análisis materialista que estudia las condiciones sociales en el interior de una formación discursiva, con atención sobre la posición social de los emisores (figuras) con las antagónicas posturas en lingüística, marxismo y psicoanálisis; esta escuela o, mejor tendencia de pensamiento, centra reflexión sobre los discursos textuales y la historia con los presupuestos del marxismo.

3 Una obra de época es: El análisis del contenido y teoria del discurso. El análisis automático del discurso parte del principio del linguistic turn que asume el lenguaje como un sistema cerrado de signos que producen sentido, esto por considerar como impersonal y automática la producción de sentido. Para ampliación. véase de Roger Chartier, El mundo como representación. Estudios de historia cultural, Barcelona, 1995, p. 5. 
La obra de M. Pêcheux, se inscribe en la denominada escuela francesa del discurso que, en los años sesenta, surge por efecto del debate interdisciplinar de época, por esto la producción intelectual de Pêcheux de base transdisciplinar presenta análisis de los procesos ideológicos en el discurso y, además, particularmente presenta estudios sobre la textualidad escrita emitida por la institucionalidad estatal con fuerte enmarcación.

El aporte metodológico de Pêcheux, se acompasa con algunas consideraciones foucualtianas, como el estudio del conjunto de reglas (anónimas e históricas) en coordenadas espacio-temporales y, el estudio de las condiciones políticas; sociales; económicas; culturales; lingüisticas y geográficas. Además, el análisis de Pêcheux contiene un corpus de enunciación o correlato con un preciso marco socio-histórico, donde la condición de las figuras o enunciadores resultan imprescindibles en el referente analítico. Por estas básicas razones, el análisis automático del discurso, es especialmente indicado para la descripción y explicación de textos escritos, a diferencia de otros análisis del discurso que, centran atención sobre aspectos sociolingüísticos de los hablantes.

Michel Pêcheux (1969) en la obra, El reconocimiento del mecanismo ideológico, precisa como la ideología no es una mentalidad de época, esto es, del modo de ideas hegemonizantes sobre politica; economía; cultura y sociedad. Precisa entonces Pêcheux, cómo la ideología no es pre existente a la lucha de clases y, esto como consecuencia metodológica hace entender que las clases sociales no prefiguran ideología previamente a las contradicciones sociales o de lucha de clases. Ahora bien, con el análisis del discurso automático la asociada cuestión de la dimensión discursiva, sostiene la consideración de la problemática articulación entre los planos enunciativos y la historia; La articulación de narración e historia, concita de manera preeminente, el estudio de la interrelación entre las dimensiones, social (material) e ideológica de los discursos, estas dimensiones, especialmente, como productoras de subjetividades en el caso de la histórica relación de ideología y poder que enmarca la historia del siglo veinte, el 'siglo de las ideologías' como adjetiva Faye.

La crítica de la razón y economía narrativa en la Teoría del Relato permite develar, por ejemplo, la producción de aceptabilidad de los vocablos; palabras-ideas; 
sintagmas (fórmulas) y secuencias de narración de los lenguajes. La crítica de la razón y economía narrativa, como elementos de la teoría fayeana, se aproxima a lo que el historiador francés Michel de Certeau (2000) en la obra, La invención de lo cotidiano, denomina la búsqueda del lugar de producción o, punto de partida, que posibilita describir el modo de producción de ideas rectoras, esto en situación, permite describir y explicar los contextos de enunciación y, explicar además cómo precisas ideas consolidan legitimidad institucional en el tiempo. En la producción, por ejemplo, de la aceptabilidad del lenguaje político en contexto histórico, elemento dominante es el emisor o mejor, figura con capacidad de producir versiones o secuencias de narración ${ }^{1}$ con fuertes trazos (bazas) de ideología política (Estadista; político profesional; líder sindical), para soportar esta perspectiva explicativa, Faye propone en la teoría una sociología del poder; ${ }^{2}$ sociología de los lenguajes políticos que, como el primero de los estadios de la Teoría del Relato, en la escritura de la historia, Faye afirma, desemboca en el problema propiamente teórico de una semántica de la historia. Todo esto: Porque la historia se desenvuelve ciertamente en el «furor del fuego fónico» y de sus «procedimientos gráficos», pero en la medida en que cada momento son articulados por la sintaxis narrativa y su interpretación semántica. (Faye, 1974, p. 10)

No obstante, Faye con el uso de la sociología del poder no presenta exhaustivo tratamiento de la categoría conceptual de ideología porque precisamente, la Teoria fayeana concede una importancia relativa a este uso categorial. La consideración metodológica fayeana de manera particular precisa como, las relaciones de dominación se hacen manifiestas y nítidas en los discursos de orden teórico e ideológico; discursos cuyo efecto de forma o de relato cuando se presentan en clave de texto escrito, permite entender los interrogantes históricos de un periodo singular, al describir y explicar los elementos de lenguaje o relato - posiblemente bastantes - que ponen, al desnudo las oscilaciones y desplazamientos en el espacio narrativo y sus cantidades de acción. (Faye, 1974. p. 139) Entonces se entiende como Faye, con la crítica de la semántica de la historia, plantea de modo fundamental,

1 Las secuencias de narración es una recepción o adopción fayeana de las «narraciones mentales», o ideas en Baruch Spinoza.

2 La 'sociología sagrada' o sociología del poder es el proyecto intelectual que lidera desde los años treinta en el colegio de Sociología de Francia los discípulos de Emil Durkheim: el antropólogo Georges Bataille, el sociólogo Roger Caillois y el etnógrafo Michel Leiris para explicar los lenguajes con orientación fascista o totalitaria. 
develar ${ }^{1}$ el sentido y la aceptabilidad de los lenguajes de la historia, esto es, en las secuencias de narración o relatos de los narradores (narus o gnarus) o historiadores (histôrs) y, para esto debe remontarlas - paradójicamente -, sin despegarse de ellas.

Faye plantea una redefinición del materialismo dialéctico, en sentido inverso al sostenido por contemporáneos suyos, ${ }^{2}$ para distinguir particularmente la dicotomía binaria ciencia/ideología que obliga a modo de corte epistemológico, una particular reflexión dialéctica sobre las prácticas teóricas ideológicas; con esto giro, Faye dibuja con el uso del materialismo dialéctico una novedosa escritura de la historia. Faye, además presenta explicaciones sobre la acción y efectos de la ideología, al proponer una crítica de la razón y economía narrativa de los lenguajes políticos; crítica que al surtirse en la superficie de los relatos de la historia, por ejemplo, permite la verificación de cambios en la narración, es decir, que devela en la trama (entramados) de las narraciones la producción de sentido y aceptabilidad en las cadenas de lenguaje, en otras palabras, crítica que permite develar la circular distribución del sentido de las ideas, método cuya paradoja debe ser el hacer coincidir el discurso teórico con la misma narración, o mejor la trama narrativa que saca a escena al analizarla. (Faye, 1974, p. 39)

Paul Ricoeur (1990) en la obra, Historia y verdad, explica como la publicación de la Ideología Alemana en 1846 de Marx y Engels - el marxismo hermenéutico -, es posible seguir dos lecturas del concepto ideología y, ambas lecturas con sus propios alcances. Una lectura es posible con el uso del enfoque estructuralista el cual comprende la consideración, de estructuras despojadas de todo individuo: la relación entre realidad e ideología corresponde a la de laestructuray superestructura, no a la que se da entre individuo y conciencia. (Hernández, Morel \& Terriles, 2011, p. 117) La otra posible lectura, parte de la consideración de la historia como dimensión contingente, por tanto, se considera que los individuos, cohabitan bajo condiciones temporalmente determinadas, esta lectura básicamente, pone de relieve el lugar de los hombres como las verdaderas víctimas de la división del trabajo y de la

1 La noción develar en la Teoría del Relato, refiere la dilucidación (desenmascaramiento) de importantes elementos en las secuencias de narración, cómo la producción de conocimiento, también entre otras: de la producción de sentido e ideología; los desplazamientos; cortes; incrustaciones; vecindades (enmarañamientos); modos de circulación de los lenguajes; razón y economía narrativa, la prosodia y, primordialmente dilucida el paso del lenguaje a la acción.

2 Como es el caso de pensadores teóricos como Louis Althusser, Paul Ricoeur, Gilles Deleuze y Michel Foucault. 
estructura de clases. (Ricoeur (1989), Ideología y Utopía. Citado por Hernández, Morel \& Terriles, 2011, p. 117) Y precisamente, en el contexto de este debate de época sobre la ideología, es que el pensador francés Michel Pêcheux con el uso de algunos principios teóricos althusserianos, explica los alcances represivos de los Aparatos Ideológicos de Estado (AIE); M. Pêcheux explica cómo estos dispositivos aparecen como una suerte de topos, lugar donde se explica la lucha de clases con sus efectos de dominación y, donde además es posible develar la reproducción/transformación de las relaciones de producción capitalista.

Ahora, subrayar como la teoria fayeana debe horizonte metodológico a la concepción materialista de la historia y, de modo particular, de la cuestión de la ideología que deriva orientación de sentido de las tesis del marxismo leniniano y althusseriano que, adjudican preponderancia de atención sobre las leyes económicas en la circulación capitalista de las mercancias. Ahora, en el clásico horizonte materialista la dimensión discursiva, no se instala en la superestructura, empero, las relaciones sociales producen sentido y con esto se debe entender que, en estricto, la estructura no discursiva, no se opone a la dimensión de la estructura discursiva; en este orden de ideas, por ejemplo, Zizek explica cómo una clasificación semántica debe preguntar sobre la manera en que un contenido particular desplaza otro contenido sustituto del universal, Zizek indica como en el caso de Laclau, este pensador resuelve el interrogante de arriba postulando la legibilidad; la legibilidad ${ }^{3}$, en el horizonte de Laclau determina una relación en que, el relato predetermina lo que experimentamos como "realidad". (Zizek, 2007, p.192)

Faye no adopta la concepción primordial del tratamiento psicoanalítico delimaginario del poder que, si aborda Pêcheux y que conduce a este pensador a definir la cuestión de la ideología en la perspectiva de los postulados lacanianos. En este entendido, la ideología en la dimensión del relato, no se agota en lo puramente lingüístico, para ilustrar, la acción ${ }^{4}$ ideológica se entrecruza con otras dimensiones

3 Slavoj Zizek explica cómo la legibilidad planteada por Ernesto Laclau no es una cuestión neutral, esta depende de una lucha ideológica, en esta lucha gana el relato más adecuado a la realidad. De manera similar Paul Ricoeur refiere esta cuestión como credibilidad y, Jean Pierre Faye denomina la cuestión como aceptabilidad. Para ampliación sobre la cuestión de la lucha ideológica véase el artículo de Slavoj Zizek, Ideología un mapa de la cuestión.

4 La acción ideológica es planteada por Faye como: «proyección ideológica» en el corpus de la Teoría del Relato, esta acción contiene la alineación de puntos de lenguaje en cierto sentido. Empero, Faye explica cómo el sentido escapa a las medidas, precisamente por las cantidades de acción que puede producir, en este sentido, se considera que la proyección ideológica, con sus oscilaciones, es un paso del lenguaje a la acción. 
como: las costumbres; la religión; la moral pública; los patrones de consumo; las relaciones laborales; las contradicciones de las clases sociales y, hasta en las intimas relaciones afectivas (por tanto los cuerpos). En resumen y a modo de fundamental consideración, Michel Foucault (1970) en el Orden del Discurso escribe que la producción del discurso es: a la vez controlada, seleccionada y redistribuida por cierto número de procedimientos que tienen por función conjurar sus poderes y peligros, dominar el acontecimiento aleatorio y esquivar su pesada y temible materialidad. (Foucault, 1970: 2)

Para Faye la crítica de la razón y economía narrativa como elemento nodal de la Teoría del Relato, esta crítica es un ejercicio crítico-racional indicado para la descripción y explicación de las rupturas o discontinuidades en los lenguajes de la historia. Además, crítica que como elemento teórico hace una calificación de veracidad, indicando la oscilación entre lo veraz y lo ficto -, que en el caso del lenguaje Político o del poder conecta la producción de sentido con la sintaxis ideológica; sintaxis que produce una prosodia política al ideologizar las secuencias de narración en los relatos. La crítica en la Teoría fayeana no se enmarca en los parámetros de la teoría clásica de la racionalidad de origen o génesis cartesiana; la crítica de la economía narrativa ${ }^{1}$ en la Teoría del Relato permite develar la producción del conocimiento que se distribuye o circula en la trama de la narraciones o, grandes operaciones del lenguaje, esto es, como explica Faye, el proceso cohesionador del relato, el proceso de la escritura del otro cuento (no menos ficto) de la historia.

La crítica de la razón y economía narrativa de las versiones o secuencias de narración puede explicar las formas de contenido y los desplazamientos lenguaticos, particularmente, los desplazamientos que se enuncian en el texto escrito; desplazamientos que como distractores ideológicos se «incrustan» en las cadenas narrativas de los distintos relatos. El proceso escritural al enunciar trazos y acentos de ideología en los fragmentos narrativos, ${ }^{2}$ de manera simultánea,

1 De acuerdo con Faye, la crítica de la economía narrativa tiene antecedente conceptual en el movimiento dialéctico de la Fenomenología del Espíritu de Hegel que, postula el Entäusserung que se traduce como «alienación», término conceptual que aparece en la crítica de Marx a la economía política capitalista. En este orden de ideas, la critica de la economía narrativa fayeana ofrece la posibilidad de estudiar los cambios del valor en las operaciones de lenguaje.

2 Los fragmentos narrativos para Baruch Spinoza es las «narraciones» y, para Ludwig Wittgenstein es las «frases narrativas». 
devela en las secuencias o intersecciones de narración el viaje de las ideas o la transmisión de los palabras-ideas (vocablos, sintagmas y fórmulas) que en el tiempo trazan indicaciones sobre la verdad (posiciones), emitida por un signo (individual o colectivo) del espectro político, a manera de un manto ideológico para manipular y conservar el poder político o, ir en pos del mismo.

El estadista y otros como: el político profesional; el funcionario público; el empresario; el religioso; el intelectual; el periodista; el médico; el sindicalista; el pedagogo y, el maestro como personas individualizadas en el horizonte de la concepción fayeana de historia fungen como figuras o actuantes (individuos singulares o personas públicas). No obstante, la noción conceptual de figura en la teoría fayeana, no se inscribe en la mirada esencialista del hombre (humanismo) y, menos se asimila con cualquiera de las múltiples acepciones de Sujeto, para Faye la figura en su singularidad histórica refiere el individuo integrado en una sociedad por la fuerza de distintos órdenes: político; jurídico-normativo; religioso; moral; cultural; económico $y$, por una dimensión exclusiva del ser humano, el poder. Las figuras al detentar representación política y social incrustan ideas (ideologia) en los discursos, de este modo entonces, más que el carácter performativo de la palabra como acción, ${ }^{3}$ es la consideración de las figuras como individuos particulares - en un tiempo y lugar preciso-, y como productores de enunciados eficaces pueden interpelar potenciales receptores. En este orden de ideas, las versiones y posiciones en los relatos de distintas figuras producen las condiciones para la aceptabilidad de los discursos, nodal noción propuesta por Faye en su Tesis doctoral. (Haidar, 2004. p. 17) En resumen, la apuesta metodológica fayeana para explicar la producción de aceptabilidad en los relatos, permite la consideración de los textos/discursos como productoresgeneradores de sentido, metodología que a la vez permite describir y explicar los procesos de recepción social de los lenguajes.

De otra parte, en torno a la cuestión de verdad en el relato, es preciso entender como en la dimensión fayeana, El relato histórico, encuentra su «verdad» en la coincidencia de dos o varias variantes narrativas, de fuentes distintas. (Faye, 1974. p.

3 El filósofo Santiago Castro-Gómez en la Historia de la gubernamentalidad, en torno a la cuestión deleuzana de la prioridad de las prácticas discursivas sobre las prácticas no discursivas, explica cómo, "lo cierto -y esto lo reconoce el propio Deleuze- es que ninguno de estos dos conjuntos goza de autonomía frente al otro". (2010, p. 66) La precisión de Castro-Gómez -considero- ayuda a comprender como la noción de acción en Faye determina significativa diferencia con la noción de práctica. Entonces, la acción se predica de figuras en particular. 
100) De este modo, en las secuencias narrativas del relato la cuestión de la verdad se debe reducir a tratar de saber, «qué hay de verdad» tras su propio relato, o a la inversa. (Faye, 1974. p. 28) Entonces, decidir entre lo veraz y lo ficto o falso, implica mirar los trazados en el terreno de la historia. (Faye, 1974, p. 28) Los trazos lenguaticos en las secuencias de narración develan acción en la narración histórica; no obstante, Faye puntualiza, que no basta con ver como se dibuja la demarcación de acción para que, enseguida desaparezca la pregunta: ¿Cómo es posible la historia desde el momento en que todos sus relatos - incluida esta o aquella narración - están en situación de ejercer una acción sobre ella? (Faye, 1974. p. 29) Independiente de las posibilidades de respuesta, capital entender que en los relatos de la historia, la veracidad o falsedad en las secuencias de narración puede, llegar a ser un elemento activo hasta el extremo de «cambiar el rostro» de la misma historia; si la trama narrativa «falsa» lleva también consigo el poder material de ejercer un efecto en tanto que relato: ¿cómo salir entonces de la «supuesta narración»?, ¿qué es la narración «verdadera»? (Faye, 1974, p. 29). Al parecer la cuestión se torna insoluble en la misma narración, entonces para Faye queda la urgente condición de adelantar una crítica de la razón y economía narrativa de los relatos; es decir, la crítica de las narraciones del narus o histôr, la crítica de la historieta o el cuento del narrador o el que conoce.

El lenguaje, nodal interés epistemológico de Jean Pierre Faye, básicamente se postula como objeto en la Teoria del Relato para lograr, una crítica de la producción de la historia «real» a través de la función narrativa misma. (Faye, 1975, pp. 29-30). Ahora, una revisión de la noción conceptual de lenguaje, igual que el caso de la noción de discurso, convoca la consideración de la argumentación de los filósofos Gilles Deleuze y Felix Guattari que, en el capitulo IV: noviembre 20 de 1923: Postulados de la lingüistica en la obra: Capitalismo y Esquizofrenia, escriben como, el lenguaje incluso no está hecho para ser creído, sino para obedecer y hacer obedecer. (Deleuze \& Guattari, 1982. p. 3). El lenguaje en la perspectiva de Deleuze-Guattari marca poder y, en similar enfoque, se entiende en la teoria de Faye, cuando por ejemplo el filósofo e historiador francés escribe sobre el poder del lenguaje político y económico al explicar cómo, La lucha de clases es completamente entretejida en y por lenguajes, incluidos los lenguajes duros de la Warensprache, de la lengua de las mercancias. (Faye, 1975, p. 37). 
En este orden de ideas, la escritura de los estudios históricos de cualquier indole (social, cultural económica o política) evidentemente, no son ajenos a los asuntos del lenguaje; esta cuestión, por ejemplo, es prevista por el notable historiador estadounidense Hayden White que en comentario sobre la obra de Reinhart Koselleck, señala como:

[...] la historia crítica y la crítica de la historia nacen de la conciencia de una discontinuidad, de una brecha dificil de salvar entre los sucesos históricos y el lenguaje usado para representarlos (ya sea por los actores contemporáneos que los vivieron, ya por los historiadores que tratan de reconstruirlos e interpretarlos a cierta distancia temporal). (Citado por Fernández \& Fuentes, 2004, pp. 12-13)

Empero, la Teoría del Relato escapa a la posible opacidad de las filosofías mediadoras del lenguaje, en contrario, la teoría fayeana devela el preciso lugar y la producción de aceptabilidad de la voz del naratur, de la voz del histôr. En este orden de ideas, Faye escribe que el relato de un historiador, es otro cuento, uno más sobre un acontecimiento. Ahora, buena parte de la obra de Faye se entiende no trata de explicar los lenguajes políticos por medio de palabras o, de presentar una historia sobre cualquier tema nacional o mundial, a partir de las palabras, precisamente Faye subraya que: En realidad, no se trata en absoluto de las «palabras», sino de «lenguajes», de los lenguajes que particularmente refieren sus acciones; es decir, de lenguajes o enunciados narrativos, de narraciones en el sentido simple y muy concreto que Spinoza ya daba a este término. (Faye 1975. p. 31) En consecuencia, la metodología fayeana impone que las secuencias de narraciones se deben tomar literalmente, esto es, estrictamente en la materialidad literal, en su «corporeidad» [...] se trata de ver dibujarse y construirse la economía, es decir los modos de producción y distribución. (Faye, 1975)

El historiador francés, plantea una nueva forma de presentar o escribir el conocimiento-histórico-, novedosa forma a partir de la dilucidación de la aceptabilidad de los emergentes lenguajes o denominadas «nuevas lenguas», esto se entiende entonces, por la producción de aceptación lenguatica que puede por ejemplo, legitimar el poder a un Estado, a un estadista o mandatario (como figura de liderazgo ideológico estatal), a un líder e incluso a organización (institución) de cualquier indole. 
En la Teoria del Relato la crítica de la razón narrativa pasa de manera previa por una crítica de la economía (producción y distribución) narrativa de los lenguajes, esto equivale a poner en la escritura del nuevo cuento o relato, una crítica razonada del lenguaje de la economía capitalista y - bien importante - además, poner en texto una crítica razonada de la economía narrativa de las ideologías políticas o de dominación de clase. Adicional, la crítica de la razón y de la economía narrativa puede develar el efecto de la resonancia ideológica de dominación en las dimensiones cultural y social, esto es, efecto que hace reflejo como un espejo (el lenguaje espejo). (Faye, 1974, p. 633) La Teoría del Relato de Faye, como articuladora de una crítica de la razón narrativa y economía narrativa parte de la mixtura del pensamiento racionalista de Kant y del crítico pensamiento de Marx; la teoría de Faye por este enfoque se encuadra en la idea universal del hombre racional, por este precepto nocional, se racionaliza el individuo en un encuadre relacional múltiple pero, con precisas coordenadas espacio-temporales; encuadre, además, donde el lenguaje enuncia, reproduce y distribuye los enunciados narrativos de la razón. La razón y con ella la crítica, en la tradición ilustrada se pueden entender como una singularidad autoritaria, esto en un topos teórico, donde la razón ilustrada, es posible de traducir como una razón carcelaria, como una forma de razón funcional. ${ }^{1}$ Ahora, el lenguaje, con la critica fayeana no se hace opaco por la razón; empero, la tradición en Occidente sostiene como la racionalidad kantiana determina de modo importante los alcances de las transformaciones de sentido en las secuencias de narración, esto es, en las unidades semánticos-gramaticales del texto escrito.

La teoria fayeana se presenta antes que la escritura de la historia en los ámbitos académicos de Europa se acepte plenamente como un relato no literario. En este orden de ideas, las obras de Paul Ricoeur, Jacques Rancière y Roger Chartier entregan interesantes argumentos sobre el trabajo y la escritura del historiador, estos autores en explicación de la producción escritural indican sobre una «poética del saber», 2 al respecto de la cuestión escribe R. Chartier:

1 Tesis filosófica que defiende el desaparecido Guillermo Hoyos. Para ampliación de G. Hoyos véase el artículo ¿Para qué Filosofia? Si "el pensar esta en lo seco", Universitas Philosphica, 27, 54, Bogotá.

2 De precisar cómo, los esfuerzos formales para constituir una «poética» se registran en el comienzo del siglo xx con la producción del grupo orientado por el teórico ruso Mijail Batjín, trabajos que en los años sesenta la filósofa y psicoanalista francesa (de origen búlgaro) Julia Kristeva retoma para enunciar el proyecto de «una ciencia de las ideologías» donde por la crítica al movimiento teórico escribe el texto: «Une poétique ruinée», esto como una respuesta crítica a la apropiación en Europa occidental del estructuralismo literario soviético. 
[...] los procedimientos literarios por los cuales un discurso se sustrae a la literatura, se da un status de ciencia y lo significa, han obligado a los historiadores, quiéranlo o no, a reconocer la pertenencia del conocimiento histórico al género del relato entendido este en sentido aristotélico, como «puesta en escena de las acciones representadas». (Chartier, 2000, p. 190)

Se considera entonces que, la producción social del conocimiento que circula en las secuencias de narraciones, presenta descripciones sobre objetos y acciones sociales, sobre esta particular dinámica de producción del conocimiento Faye afirma que, si hay que colocarle un nombre es el de la historia misma. Asi se entiende como la Teoría del Relato, permite develar la estrecha relación entre lenguajeconocimiento e historia pero, la historia no como una ciencia complementaria sino, como un objeto de dominio lingüístico que, además, como saber disciplinar permite re pensar la tradición del oficio historiador. En consecuencia, el estudio del lenguaje-conocimiento, se inscribe, en un ámbito de relaciones topológicas y lógicas. (Faye, 1975. p.75) El espacio topológico, en la perspectiva fayeana indica una topografía abstracta (sin «medidas») para calcular, las distancias y vecindades entre las cadenas de enunciados, con sus formas de tesis (fórmulas) y antítesis o, de oposiciones diametrales. Empero, la axial tarea de explicar la aceptabilidad de los lenguajes, no implica como escribe Faye, de caer en la trampa, también ideológica, de mostrar en un estudio histórico simplemente lo que dicen los hombres. En contrario, se parte de hombres reales o, mejor como explica el pensador francés: Se parte de hombres realmente activos, y a partir de su proceso vital real, es como se representa igualmente el desarrollo de los reflejos ideológicos y de los ecos ideológicos de ese proceso vital. (Faye, 1975. p. 82)

Con el uso de la Teoria del Relato en la escritura de la historia, se precisa la producción de la aceptabilidad de los lenguajes, ese producto social que es un enunciado informante; de modo capital se trata de entender lo que hacen los hombres al pronunciarlo. (Faye, 1975, p. 82) En la circulación de los discursos, el enunciado informante o informador, cuando se pronuncia, como escriben Deleuze y Guattari (1982), se debe entender que es información, no una organización de significaciones preestablecidas de unidades de discurso. En este orden de ideas, en los estudios históricos con la perspectiva fayeana se trata, de determinar específicamente la 
aceptabilidad de los lenguajes con sus discursos oficiales y públicos (legitimados) y, de estudiar las acciones - con sus efectos - de las figuras con vida pública activa. En el lenguaje y, con este los enunciados, los vocablos o palabras pueden tener el uso de consignas; fórmulas o consignas que como mandatos resultan lingüisticamente en una coextensión del lenguaje.

La Teoria del Relato de Faye puede historiar o historizar los eventos y acontecimientos (trascendentes motivos históricos) como las crisis económicas y los conflictos sociales, a veces, en la contempóranea inédita forma de lucha de clases (la articulación de clases como escribe a veces Marx) que determinan para Faye, en ocasiones las revoluciones retrogradas o, las revoluciones antagónicas anunciadas por la clásica previsión de Marx. Elhistoriador francés, consecuente con la orientación materialista marxista, privilegia la teoria de las clases sociales en la dimensión del conflicto social, esto como un básico rol de juego en un preciso momento histórico. Faye, además, como intelectual de época, se inscribe en el debate de la crítica de las ciencias sociales; critica que en el particular caso, de buena parte de la obra del pensador francés, se enuncia con una mixtura de pensamiento francfortiano y epistemología francesa.

En resumen, al precisar las posibilidades de la Teoria del Relato, ${ }^{1}$ se entiende como primordial develar el paso del lenguaje a la acción, por esto el referido historiador considera que: Son los cortes, son los traslados de una cadena de lenguaje de otra, esa especie de «prosodia» de las lenguas políticas lo que se encuentra, aquí, ligado a la concepción de la acción. (Faye, 1974, p. 11) En último, Chartier, en torno a las posibilidades metodológicas del relato para la escritura de la historia, explica como:

Ese reflujo hacia el Relato (el relato verídico de la historia) significa una renuncia a las explicaciones coherentes y cientificas (en particular a las proporcionadas por las causalidades económicas y demográficas) [... indica un desplazamiento de los objetos (que ya no son las estructuras sociales sino los sentimientos, los valores, los comportamientos), de los tratamientos (los procedimientos cuantitativos

1 Importante precisar que la Teoría del Relato, no es una teoría de la Historia, esta Teoría se debe entender como una topografía política y, además como una «topología semántica» que sitúa las figuras (individuos) con sus relatos (narraciones) en la historia. 
ceden ante la investigación de particularidades) y de la comprensión histórica (el 'principio de indeterminación' que sustituye los modelos deterministas). (Chartier. 1995, p. 74)

Chartier, resulta prácticamente insuperable en la apreciación sobre las posibilidades del relato para la tradición de la escritura de la historia; de este modo, se entiende como el historiador francés Jean Pierre Faye, definitivamente, no es un solitario en su concepción de la historia como relato. Con todo, se confirma que la epistemología francesa es generosa en posibilidades para las Ciencias Sociales; en consecuencia, dable afirmar que la Teoria del Relato permite efectivamente estudiar, entre muchos elementos de los lenguajes, particularmente, la «prosodia» de las narraciones míticas (los cuentos fictos) que se producen y circulan en casi todos los relatos. 


\section{Referencias.}

Castro-Gómez, S. (2010). La historia de la Gubernamentalidad. Razón de Estado, liberalismo y neoliberalismo en Michel Foucault. Bogotá D.C. Siglo del Hombre Editores.

Chartier, R. (1995). El Mundo como representación, Estudios sobre historia cultural. Barcelona, Gedisa $2^{\mathrm{a}}$ edición.

(2000). La historia entre relato y conocimiento, traducción de Renán Silva con autorización delautor, Revista Historia y Espacio, 17, enero-junio 2000, Cali: Universidad del Valle.

Deleuze, G. \& Guattari, F. (1982). Noviembre 23: Postulados de lingüística. Ciencias Humanas, 2, 2, 1982.

Faye, J. P. (1974). Lenguajes Totalitarios. Madrid, Taurus.

(1975). La Crítica del Lenguaje y su economía. Madrid, Alberto Corazón.

Fernández, S. J. \& Fuentes, J.F. (2004). A manera de Introducción. Historia, lenguaje y política. Ayer, 53, 2004.

Foucault, M. (1970). El orden del discurso, Lección inaugural pronunciada en el Collage de France el 2 de diciembre de 1.970, Recuperado de: http://espanol.freeebooks.net/tos.html.

Haidar, J. (2004). El campo del Análisis del Discurso: aportes para el estudio de lo político. Pensamiento Contemporáneo, (6), Santo Domingo: Fundación Global Democracia y Desarrollo, Colección Pensamiento Contemporáneo.

Hernández, S; Morel, P. \& Terriles, R. (2011). Discurso y sujeto en las perspectivas de Pécheux y Voloshinov. Contratexto, 19, Universidad de Buenos Aires.

Hoyos, G. (2010). ¿Para qué Filosofía?, Si "El pensar está en lo seco". Universitas Philosophica, 27, 54, Bogotá. 
Pêcheux, M. (1969). Análisis del contenidoy teoria del discurso. En: Análisis Automático del Discurso, Dunod, París. Recuperado de: http://www.filo.uba.ar/contenidos/ carreras/letras/catedras/sociolinguistica/sitio/pecheux.pdf.

Zizek, S. (2007). El espinoso sujeto. El centro ausente de la ontología politica, Buenos Aires, Paidós, $2^{\mathrm{a}}$ reimpresión. 